\title{
Where Stochastic OT fails: a discrete model of metrical variation
}

\author{
Paul Kiparsky \\ Stanford University
}

In a remarkable confirmation of OT in an empirical domain for which it was not originally intended, phonological and morphological variation has been successfully modeled by partially ranked categorical constraints (Anttila 1997, 2002). Poetic meter is a good place to extend and test this approach to variation, because there is abundant and diverse quantitative data available for it, and because it is typically governed by a relatively small number of well-understood constraints. I report the results of four such studies here. They confirm that choices among metrical options are governed by the interaction of partially ranked constraints, in each case constraints that are grounded, and motivated independently of variation data by related systems in which they have a fixed rank. The partially ranked constraint systems turned out to predict not only the relative preferences among metrical options, but also their actual frequencies in the corpora, with surprising accuracy. These findings support the partial ranking model of variation, and provide an explanatory benchmark beyond the reach of intrinsically weaker stochastic approaches that posit a statistical component for metrical competence (Hayes \& MacEachern 1998).

We derive the distribution of verse types by constraint systems which are formally analogous to grammatical constraint systems in the following respects.

(1) a. The constraint systems accept any input and generate well-formed verse types as outputs.

b. Constraints are partially ranked. We consider the set of fully ranked constraint systems consistent with the permitted rankings.

c. $\mathrm{M}$ is METRICAL if it is the optimal output in at least one such constraint system for at least one input.

d. The frequency of a verse type is proportional to the number of constraint systems in which it is the optimal output for some input.

The first two studies investigate the quatrain form of traditional English ballads and hymns; they are reported more fully in Kiparsky 2005a, with discussion of Hayes \& MacEachern 1998.

\section{Case 1: English folk songs}

This song was sung by Mr. Bridges for Cecil Sharp and Maud Karpeles in Franklin County, Virginia in 1918: 

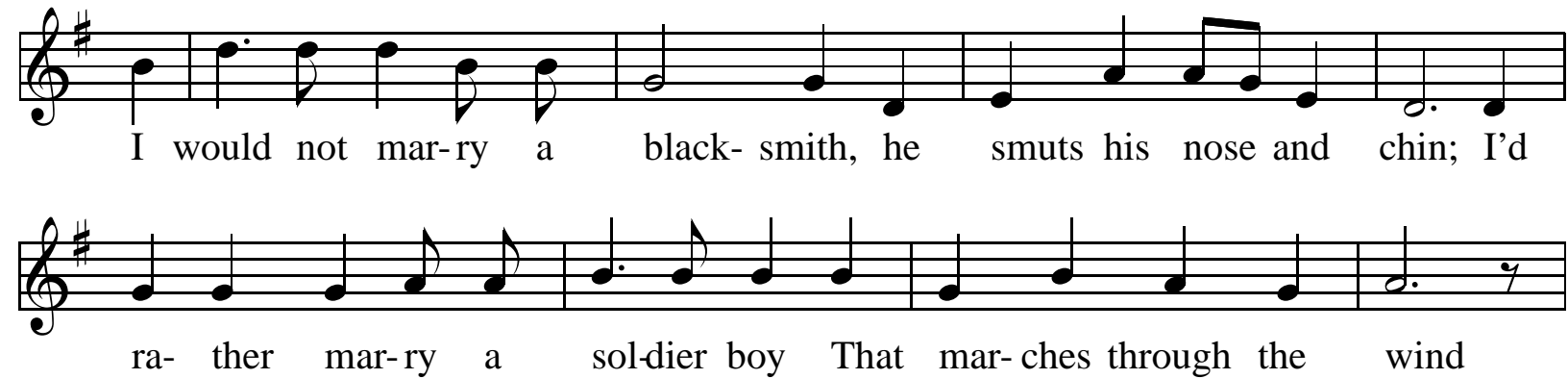

Like many folk songs, it has variant versions (I would not marry a railroad man, I would not marry a farmer...) and singers can readily improvise new ones. But every version adheres to a fixed hierarchical structure in which each unit, from the quatrain all the way down to the foot, is made up of exactly two units of the next lower level. This is the meter of the vast majority of ballads, hymns, and popular songs.

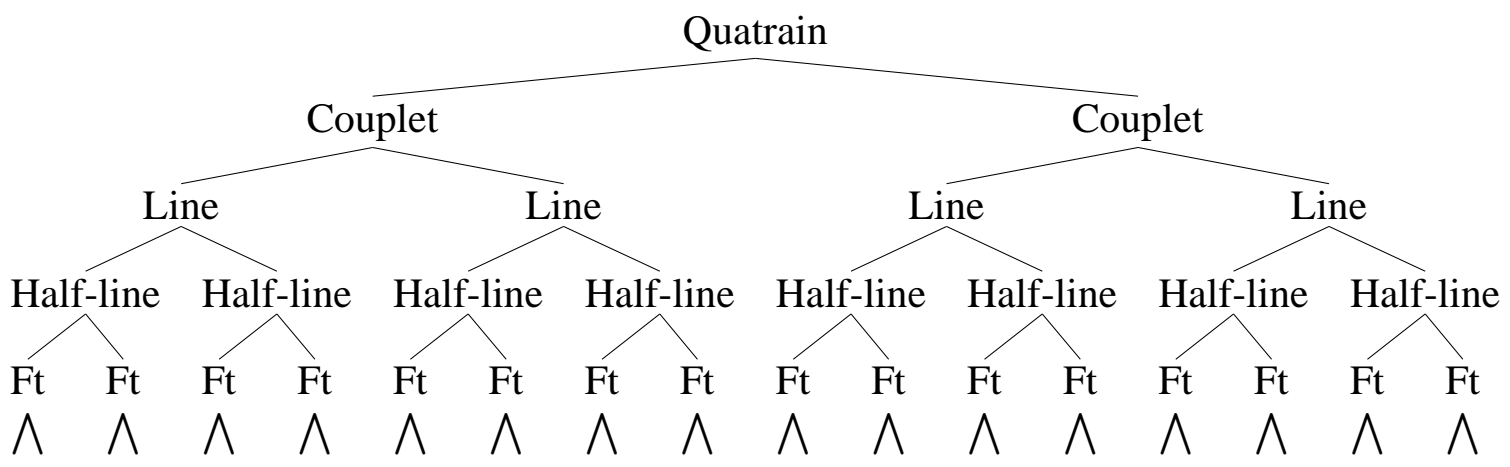

The most important site of metrical variation in this meter is the cadence of the line, its fourth foot (Hayes \& MacEachern 1998). It can be binary, unary, or empty, and lines with those cadences are respectively classified as Type $\mathbf{4}, \mathbf{3}^{\prime}$, and $\mathbf{3}^{1}$
a. I wóuld $\mid$ not már|ry a bláck|—-smíth, (Type $\mathbf{3}^{\prime}$ )
b. He smúts $\mid$ his nóse $\mid$ and chín; $\mid \emptyset$
(Type 3)
c. I'd rá|ther már|ry a sól|dier bóy
(Type 4)
d That már|ches thróugh $\mid$ the wínd. $\mid \emptyset \quad$ (Type 3)

Their grid representations (from Hayes \& MacEachern 1998) are shown in (4).

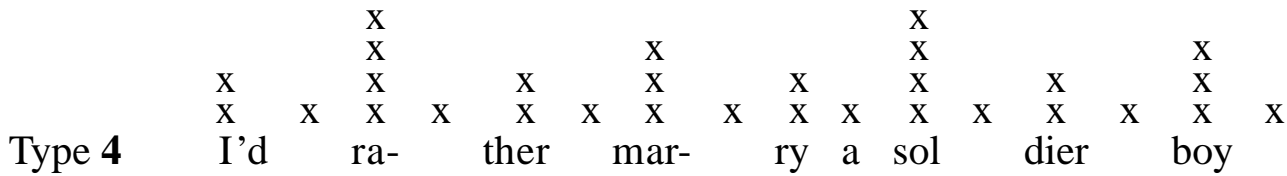

\begin{tabular}{|c|c|c|c|c|c|c|c|c|c|c|c|c|c|c|c|}
\hline & & & $\mathrm{X}$ & & & & & & & & $\mathrm{X}$ & & & & \\
\hline & & & $\mathrm{X}$ & & & & $\mathrm{X}$ & & & & $\mathrm{X}$ & & & & $\mathrm{X}$ \\
\hline & $\begin{array}{l}\mathrm{X} \\
\mathrm{X}\end{array}$ & $\mathrm{X}$ & $\begin{array}{l}\mathrm{X} \\
\mathrm{X}\end{array}$ & $\mathrm{X}$ & $\begin{array}{l}\mathrm{X} \\
\mathrm{X}\end{array}$ & $\mathrm{X}$ & $\begin{array}{l}\mathrm{X} \\
\mathrm{X}\end{array}$ & $\mathrm{X}$ & $\begin{array}{l}\mathrm{X} \\
\mathrm{X}\end{array}$ & $\mathrm{X}$ & $\begin{array}{l}\mathrm{X} \\
\mathrm{X}\end{array}$ & $\mathrm{X}$ & $\begin{array}{l}\mathrm{X} \\
\mathrm{X}\end{array}$ & X & $\begin{array}{l}\mathrm{X} \\
\mathrm{X}\end{array}$ \\
\hline ype $3^{\prime}$ & I & & would & & not & & mar & ry & $\mathrm{a}$ & & black & & & & smith \\
\hline
\end{tabular}

\footnotetext{
${ }^{1}$ Hayes \& MacEachern 1998 actually distinguish more types; the three-way classification adopted here is justified in Kiparsky 2005a.
} 


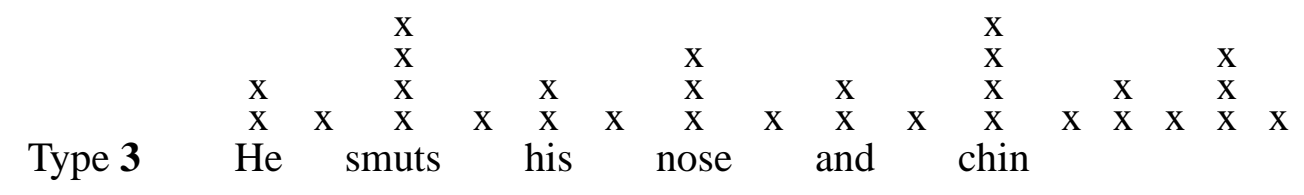

The distribution of line types in quatrains is strictly regulated. From the three line types $\mathbf{4}, \mathbf{3}^{\prime}$, and $\mathbf{3}$ it is theoretically possible to form nine types of couplets, of which six exist:
a. occurring couplet types: $44,43^{\prime}, 43,3^{\prime} 3^{\prime}, 3^{\prime} 3$, and 33 ,
b. non-occuring couplet types: $\mathbf{3}^{\prime} \mathbf{4}, \mathbf{3 4}$, and $\mathbf{3 3}^{\prime}$.

The three missing couplet types are just those whose second line is longer than the first. Let us model this as the requirement that a couplet must satisfy one of the two constraints in (8) (it obviously cannot satisfy both).

a. Parallelism: A couplet is parallel (its lines are alike).

b. SALIENCY: A couplet is salient (its second line is shorter).

Couplet types $43^{\prime}, \mathbf{4 3}, 3^{\prime} \mathbf{3}$ satisfy SALIENCY, couplet types $44,3^{\prime} 3^{\prime}, \mathbf{3 3}$, satisfy PARALLELISM, and the missing couplet types $\mathbf{3}^{\prime} \mathbf{4}, \mathbf{3 4}$, and $\mathbf{3 3}^{\prime}$ satisfy neither.

It may seem odd to call shorter lines salient. Should not saliency on the contrary correlate with length? In a sense that is precisely what it does here. Sung to a fixed melody, each line takes up the same amount of musical bars or grid space, and the endings of shorter lines are lengthened to fill that allotted space. This elongation seems to behind the perceptual saliency of the lines with fewer syllables.

From the six occurring couplet types it is theoretically possible to form 36 types of quatrains, of which nine exist, as indicated below by the parenthesized figures showing the number of occurrences in the corpus of MacEachern \& Hayes 1998.

(7)

\begin{tabular}{|c|c|c|c|c|c|c|}
\hline & a. 44 & b. 43 & c. $\mathbf{4 3}^{\prime}$ & d. $\mathbf{3}^{\prime} \mathbf{3}^{\prime}$ & e. $\mathbf{3}^{\prime} \mathbf{3}$ & f. 33 \\
\hline 1. 44 & $\begin{array}{l}4444 \\
\text { (203) }\end{array}$ & $\begin{array}{c}4443 \\
(35)\end{array}$ & $4443^{\prime}$ & $443^{\prime} 3^{\prime}$ & $443^{\prime} 3$ & $\begin{array}{c}4433 \\
(1)\end{array}$ \\
\hline 2.43 & $\begin{array}{c}4344 \\
\text { (1) }\end{array}$ & $\begin{array}{l}4343 \\
(188)\end{array}$ & $\begin{array}{c}4343^{\prime} \\
(1)\end{array}$ & $433^{\prime} 3^{\prime}$ & $433^{\prime} 3$ & 4333 \\
\hline 3. $43^{\prime}$ & $43^{\prime} 44$ & $43^{\prime} 43$ & $\begin{array}{c}43^{\prime} 43^{\prime} \\
(64)\end{array}$ & $43^{\prime} 3^{\prime} 3^{\prime}$ & $\begin{array}{c}43^{\prime} 3^{\prime} 3 \\
(1)\end{array}$ & $43^{\prime} 33$ \\
\hline 4. $\mathbf{3}^{\prime} \mathbf{3}^{\prime}$ & $3^{\prime} 3^{\prime} 44$ & $3^{\prime} 3^{\prime} 43$ & $3^{\prime} 3^{\prime} 43^{\prime}$ & $\begin{array}{c}3^{\prime} 3^{\prime} 3^{\prime} 3^{\prime} \\
(5)\end{array}$ & $3^{\prime} 3^{\prime} 3^{\prime} 3$ & $3^{\prime} 3^{\prime} 33$ \\
\hline $5.3^{\prime} 3$ & $3^{\prime} 344$ & $\begin{array}{c}3^{\prime} 343 \\
(8)\end{array}$ & $3^{\prime} 343^{\prime}$ & $3^{\prime} 33^{\prime} 3^{\prime}$ & $\begin{array}{c}3^{\prime} 33^{\prime} 3 \\
(84)\end{array}$ & $\begin{array}{c}3^{\prime} 333 \\
(1)\end{array}$ \\
\hline 6. 33 & 3344 & $\begin{array}{c}3343 \\
(6)\end{array}$ & $3343^{\prime}$ & $333^{\prime} 3^{\prime}$ & $\begin{array}{c}333^{\prime} 3 \\
(1)\end{array}$ & $\begin{array}{c}3333 \\
(1)\end{array}$ \\
\hline
\end{tabular}

Most of the occurring quatrain types are lined up along the NW/SE diagonal, in roughly descending frequency, with a smaller group down the second column (column b), but skipping two of the cells ( $3 \mathrm{~b}$ and $4 \mathrm{~b}$ ). To a first approximation we can say that the two couplets of a rhyming quatrain must either be parallel (the diagonal), or the second of them must be a maximally salient couplet 43 (column b). This suggests that quatrains are built from couplets by a similar principle 
by which couplets are built from lines: quatrains must be composed of parallel couplets, or their second couplet must be maximally salient, which is to say $\mathbf{4 3}$.

a. PARAllelism: A quatrain is parallel (its couplets are alike).

b. SALIENCY: A quatrain is salient (its second couplet is $\mathbf{4 3}$ ).

The shaded cells in (9) are the quatrain types which do not conform to either (8a) or (8b). The shading correctly excludes all the non-occurring quatrain types (assuming that the stray singletons fall outside the systematic inventory), except for the two in cells (3b) and (4b), which are still incorrectly admitted

(9)

\begin{tabular}{|c|c|c|c|c|c|c|}
\hline & a. 44 & b. 43 & c. $\mathbf{4 3}^{\prime}$ & d. $\mathbf{3}^{\prime} \mathbf{3}^{\prime}$ & e. $3^{\prime} 3$ & f. 33 \\
\hline 1. 44 & $\begin{array}{l}4444 \\
\text { (203) }\end{array}$ & $\begin{array}{c}4443 \\
(35)\end{array}$ & $4443^{\prime}$ & $443^{\prime} 3^{\prime}$ & $443^{\prime} 3$ & $\begin{array}{c}4433 \\
\text { (1) }\end{array}$ \\
\hline 2. 43 & $\begin{array}{c}4344 \\
(1)\end{array}$ & $\begin{array}{l}4343 \\
(188)\end{array}$ & $\begin{array}{c}4343^{\prime} \\
(1) \\
\end{array}$ & $433^{\prime} 3^{\prime}$ & $433^{\prime} 3$ & 4333 \\
\hline 3. $\mathbf{4 3}^{\prime}$ & $43^{\prime} 44$ & $43^{\prime} 43$ & $\begin{array}{c}43^{\prime} 43^{\prime} \\
(64)\end{array}$ & $43^{\prime} 3^{\prime} 3^{\prime}$ & $\begin{array}{c}43^{\prime} 3^{\prime} 3 \\
(1)\end{array}$ & $43^{\prime} 33$ \\
\hline 4. $\mathbf{3}^{\prime} \mathbf{3}^{\prime}$ & $3^{\prime} 3^{\prime} 44$ & $3^{\prime} 3^{\prime} 43$ & $3^{\prime} 3^{\prime} 43^{\prime}$ & $\begin{array}{c}3^{\prime} 3^{\prime} 3^{\prime} 3^{\prime} \\
(5)\end{array}$ & $3^{\prime} 3^{\prime} 3^{\prime} 3$ & $3^{\prime} 3^{\prime} 33$ \\
\hline $5.3^{\prime} 3$ & $3^{\prime} 344$ & $\begin{array}{c}3^{\prime} 343 \\
(8) \\
\end{array}$ & $3^{\prime} 343^{\prime}$ & $3^{\prime} 33^{\prime} 3^{\prime}$ & $\begin{array}{c}3^{\prime} 33^{\prime} 3 \\
(84)\end{array}$ & $\begin{array}{c}3^{\prime} 333 \\
(1) \\
\end{array}$ \\
\hline 6. 33 & 3344 & $\begin{array}{c}3343 \\
(6)\end{array}$ & $3343^{\prime}$ & $333^{\prime} 3^{\prime}$ & $\begin{array}{c}333^{\prime} 3 \\
(1)\end{array}$ & $\begin{array}{c}3333 \\
\text { (1) }\end{array}$ \\
\hline
\end{tabular}

(3b) and (4b) are not unmetrical; the reason they do not occur is that they normally cannot fulfill the requirement that couplets of a quatrain must rhyme with each other. Since $\mathbf{3}^{\prime}$ cannot rhyme with 3 or 4 (riding and king do not rhyme), both couplets of a quatrain must be either $\mathbf{4 4}, \mathbf{4 3}, \mathbf{3}^{\prime} \mathbf{3}$, $\mathbf{3 3}$ or $\mathbf{4 3}^{\prime}, \mathbf{3 3}^{\prime}$. This rhyming requirement excludes the sixteen unwanted dark-shaded quatrains in (10), including the ones that were not already discarded by (8).

\begin{tabular}{|c|c|c|c|c|c|c|}
\hline & a. 44 & b. 43 & c. $\mathbf{4 3}^{\prime}$ & d. $\mathbf{3}^{\prime} \mathbf{3}^{\prime}$ & e. $3^{\prime} \mathbf{3}$ & f. $\mathbf{3 3}$ \\
\hline 1. 44 & $\begin{array}{l}4444 \\
(203)\end{array}$ & $\begin{array}{c}4443 \\
(35)\end{array}$ & $\overline{4443^{\prime}}$ & $4443^{\prime} 3^{\prime}$ & $443^{\prime} 3$ & $\begin{array}{c}4433 \\
(1)\end{array}$ \\
\hline 2. 43 & $\begin{array}{c}4344 \\
\text { (1) }\end{array}$ & $\begin{array}{l}4343 \\
(188)\end{array}$ & $\begin{array}{c}4343^{\prime} \\
\text { (1) }\end{array}$ & $433^{\prime} 3^{\prime}$ & $433^{\prime} 3$ & 4333 \\
\hline 3. $43^{\prime}$ & $43^{\prime} 44$ & $43^{\prime} 43$ & $\begin{array}{c}43^{\prime} 43^{\prime} \\
(64)\end{array}$ & $43^{\prime} 3^{\prime} 3^{\prime}$ & $43^{\prime} 3^{\prime} 3$ & $43^{\prime} 33$ \\
\hline 4. $\mathbf{3}^{\prime} \mathbf{3}^{\prime}$ & $3^{\prime} 3^{\prime} 44$ & $3^{\prime} 3^{\prime} 43$ & $3^{\prime} 3^{\prime} 43^{\prime}$ & $\begin{array}{c}3^{\prime} 3^{\prime} 3^{\prime} 3^{\prime} \\
(5)\end{array}$ & $3^{\prime} 3^{\prime} 3^{\prime} 3$ & $3^{\prime} 3^{\prime} 33$ \\
\hline $5 . \mathbf{3}^{\prime} \mathbf{3}$ & $3^{\prime} 344$ & $\begin{array}{c}3^{\prime} 343 \\
(8)\end{array}$ & $3^{\prime} 343^{\prime}$ & $3^{\prime} 33^{\prime} 3^{\prime}$ & $\begin{array}{c}3^{\prime} 33^{\prime} 3 \\
(84)\end{array}$ & $3^{\prime} 333$ \\
\hline 6. 33 & 3344 & $\begin{array}{c}3343 \\
(6)\end{array}$ & $3343^{\prime}$ & $333^{\prime} 3^{\prime}$ & $333^{\prime} 3$ & $\begin{array}{c}3333 \\
(1)\end{array}$ \\
\hline
\end{tabular}

To complete the analysis, we add two more constraints to PARALLELISM and SALIENCY. They are the standard constraints on foot well-formedness that mandate binary feet with no empty positions. 
a. Parallelism: Constituents are parallel. (satisfied by $\mathbf{4 4 ,} \mathbf{3}^{\prime} \mathbf{3}^{\prime}, \mathbf{3 3}$ )

b. SALIENCY: Constituents are salient. (satisfied by $\mathbf{4 3}, \mathbf{4 3}^{\prime}, \mathbf{3}^{\prime} \mathbf{3}$ )

c. MAXBEAT: Beats are realized. (satisfied by $\mathbf{4 4}$ )

d. FootBin: Feet are binary. (satisfied by $44, \mathbf{4 3}, \mathbf{3 3}, \mathbf{3 4}$ )

Although MAXBEAT and FoOTBIN are violable in ballad quatrains, they occur as obligatory undominated constraints in many other meters. In fact, they are undominated in all meters that we will encounter in the rest of this paper. ${ }^{2}$ So the theory we are working with actually predicts that they should play a role in shaping the patterns of variation in ballad quantrains too.

Since all possible rankings of (11) yield either $\mathbf{4 3}$ or $\mathbf{4 4}$, at least one other constraint must be added to derive the other types. And beause it must defeat markedness constraints, we know that it must belong to the FAITHFULNESS family. For our purposes we only need the most general constraint of the family, which enjoins that the input is realized (rather than being replaced by something else, or suppressed).

(12) FAithfulness: The input and output are identical.

We now have a set of correspondence constraints that map arbitrary inputs into their optimal metrical scansions. Here is how the system works:

a. Unmetrical inputs are ruled out by constraints that dominate FAITHFULNESS.

b. Metrical inputs are mapped into identical outputs just in case FAITHFULNESS dominates all constraints that defeat them.

c. Otherwise they are mapped into more harmonic outputs.

The effect of FAITHFULNESS is to license any candidate not excluded by higher-ranked constraints as metrical. Constraints ranked above this cutoff-point restrict metricality, while constraints ranked below it are inactive. M is METRICAL with respect to a constraint system if it is the optimal output for some input. To determine the metricality of a given output we need only consider the derivation in which it is identical to the input, for it always harmonically bounds the others. For example, under the constraint ranking in (26), $\mathbf{4 4}$ is unmetrical and $\mathbf{4 3}^{\prime}$ is metrical.

\begin{tabular}{|ll||c|c|c|c|c|l|l|l|l|l|l|l|}
\hline Input: $\mathbf{4 4}$ & SAL & PAR & FAITH & FTBIN & MAX & Input: $\mathbf{4 3}^{\prime}$ & SAL & PAR & FAITH & FTBIN & MAX \\
\hline \hline $1 . \mathbf{x} \mathbf{4 4}$ & $*$ & & & & & 1. & $\mathbf{4 4}$ & $*$ & & $*$ & & \\
\hline 2. & $\mathbf{4 3}$ & & $*$ & $*$ & $*$ & $*$ & 2. & $\mathbf{4 3}$ & & $*$ & & $*$ & $*$ \\
\hline 3. & $\mathbf{4 3}$ & & $*$ & $*$ & & $*$ & 3. & $\mathbf{4 3}$ & & $*$ & $*$ & & $*$ \\
\hline 4. & $\mathbf{3}^{\prime} \mathbf{3}^{\prime}$ & $*$ & & $*$ & $*$ & $*$ & 4. & $\mathbf{3}^{\prime} \mathbf{3}^{\prime}$ & $*$ & & $*$ & $*$ & $*$ \\
\hline 5. & $\mathbf{3}^{\prime} \mathbf{3}$ & & $*$ & $*$ & $*$ & $*$ & 5. & $\mathbf{3}^{\prime} \mathbf{3}$ & & $*$ & $*$ & $*$ & $*$ \\
\hline 6. & $\mathbf{3 3}$ & $*$ & & $*$ & & $*$ & 6. & $\mathbf{3 3}$ & $*$ & & $*$ & & $*$ \\
\hline 7. & $\mathbf{3 4}$ & $*$ & $*$ & $*$ & & $*$ & 7. & $\mathbf{3 4}$ & $*$ & $*$ & $*$ & & $*$ \\
\hline 8. & $\mathbf{3 3}^{\prime}$ & $*$ & $*$ & $*$ & $*$ & $*$ & 8. & $\mathbf{3 3}^{\prime}$ & $*$ & $*$ & $*$ & $*$ & $*$ \\
\hline 9. & $\mathbf{3}^{\prime} \mathbf{4}$ & $*$ & $*$ & $*$ & $*$ & $*$ & 9. & $\mathbf{3}^{\prime} \mathbf{4}$ & $*$ & $*$ & $*$ & $*$ & $*$ \\
\hline \hline
\end{tabular}

While FAITHFULNESS must be able to outrank some markedness constraints so that types $\mathbf{3}^{\prime} \mathbf{3}^{\prime}$, $\mathbf{3 3}, \mathbf{4 3}^{\prime}$ and $\mathbf{3}^{\prime} \mathbf{3}$ can be derived (as (26) illustrates), it cannot freely outrank all the markedness constraints, or else the unmetrical couplet types $* \mathbf{3 4}, \mathbf{*}^{\prime} \mathbf{4},{ }^{*} \mathbf{3}^{\prime} \mathbf{3}$ will also be derived. Since the unmetrical couplets violate both SALIENCY and PARALLELISM, either one of the following rankings will exclude them.

\footnotetext{
${ }^{2}$ MAXBEAT appears under the name of FILL in section 3.
} 


\section{a. SALIENCY $\gg$ FAITHFULNESS \\ b. PARALlelism $\gg$ FAithfulness}

It turns out that (15a) also predicts the observed frequencies in (10), assuming the simple principle in (1d) that frequency of a line type is proportional to the number of tableaux in which it is optimal for some input.

The frequency predictions can be conveniently calculated by compiling a tableau of tableaux. (16) lists all 24 rankings of the four constraints in (22), followed by four columns representing the ranking of FAITHFULNESS among them in second, third, fourth, and fifth position, respectively. (It cannot be ranked in first position because of (15a)). Each of the 96 cells on the right side represents a tableau for a different ranking of the five constraints, and its contents show the possible outputs of that tableau for the totality of inputs. The 36 shaded cells represent tableaux excluded by the fixed ranking (15a)), and the remaining 60 unshaded cells represent the permissible tableaux. To get the predicted frequencies of the outputs we count the number of times they appear in the unshaded cells and convert them into percentages.

\begin{tabular}{|c|c|c|c|c|c|c|c|}
\hline \multicolumn{4}{|c|}{ Ranking of markedness constraints } & \multicolumn{4}{|c|}{ Ranking of FAITHFULNESS } \\
\hline & & & & 2nd & 3rd & 4th & 5 th \\
\hline$\overline{\mathrm{SAL}}$ & MAX & FTBIN & PAR & $4343^{\prime} 3^{\prime} 3$ & $4343^{\prime} 3^{\prime \prime} 3$ & 43 & 43 \\
\hline SAL & MAX & PAR & FTBIN & $4343^{\prime} 3^{\prime} 3$ & $4343^{\prime} 3^{\prime} 3$ & $4343^{\prime} 3^{\prime} 3$ & 43 \\
\hline SAL & FTBIN & MAX & PAR & $4343^{\prime} 3^{\prime} 3$ & 43 & 43 & 43 \\
\hline SAL & FTBIN & PAR & MAX & $4343^{\prime} 3^{\prime} 3$ & 43 & 43 & 43 \\
\hline SAL & PAR & MAX & FTBIN & $4343^{\prime} 3^{\prime} 3$ & $4343^{\prime} 3^{\prime} 3$ & $4343^{\prime} 3^{\prime} 3$ & 43 \\
\hline SAL & PAR & FTBIN & MAX & $4343^{\prime} 3^{\prime} 3$ & $4343^{\prime} 3^{\prime \prime} 3$ & 43 & 43 \\
\hline$\overline{\text { MAX }}$ & $\overline{\mathrm{SAL}}$ & FTBIN & PAR & 44 & 44 & 44 & 44 \\
\hline MAX & SAL & PAR & FTBIN & 44 & 44 & 44 & 44 \\
\hline FTBIN & SAL & PAR & MAX & 4443 & 43 & 43 & 43 \\
\hline FTBIN & SAL & MAX & PAR & 4443 & 43 & 43 & 43 \\
\hline PAR & SAL & MAX & FTBIN & $443^{\prime} 3^{\prime} 33$ & $443^{\prime} 3^{\prime} 33$ & 44 & 44 \\
\hline PAR & SAL & FTBIN & MAX & $443^{\prime} 3^{\prime} 33$ & $443^{\prime} 3^{\prime} 33$ & 4433 & 44 \\
\hline MAX & FTBIN & SAL & PAR & 44 & 44 & 44 & 44 \\
\hline MAX & PAR & SAL & FTBIN & 44 & 44 & 44 & 44 \\
\hline FTBIN & MAX & SAL & PAR & 44 & 44 & 44 & 44 \\
\hline FTBIN & PAR & SAL & MAX & 444333 & 4433 & 4433 & 44 \\
\hline PAR & MAX & SAL & FTBIN & $443^{\prime} 3^{\prime} 33$ & 44 & 44 & 44 \\
\hline PAR & FTBIN & SAL & MAX & $443^{\prime} 3^{\prime} 33$ & 4433 & 4433 & 44 \\
\hline MAX & FTBIN & PAR & $\mathrm{SAL}$ & 44 & 44 & 44 & 44 \\
\hline MAX & PAR & FTBIN & SAL & 44 & 44 & 44 & 44 \\
\hline FTBIN & MAX & PAR & SAL & 44 & 44 & 44 & 44 \\
\hline FTBIN & PAR & MAX & SAL & 4443 & 44 & 44 & 44 \\
\hline PAR & MAX & FTBIN & SAL & $443^{\prime} 3^{\prime} 33$ & 44 & 44 & 44 \\
\hline PAR & FTBIN & MAX & SAL & $443^{\prime} 3^{\prime} 33$ & 4433 & 44 & 44 \\
\hline
\end{tabular}

The expected couplet frequencies determined by this method from (16) are compared in (17) with the corresponding actual couplet frequencies computed from M\&H's corpus. 
(17)

\begin{tabular}{|l|rr|rr|}
\hline Type & \multicolumn{2}{|r|}{ frequency in tableaux } & \multicolumn{2}{|c|}{ frequency in corpus } \\
\hline 44 & $33 \%$ & $(30$ tableaux $)$ & $37 \%$ & $(461$ couplets $)$ \\
43 & $33 \%$ & $(30$ tableaux $)$ & $35 \%$ & $(433$ couplets $)$ \\
\hline $43^{\prime}$ & $13 \%$ & $(12$ tableaux $)$ & $12 \%$ & $(144$ couplets $)$ \\
$3^{\prime} 3$ & $13 \%$ & $(12$ tableaux $)$ & $15 \%$ & $(183$ couplets $)$ \\
\hline $3^{\prime} 3^{\prime}$ & $4 \%$ & $(4$ tableaux $)$ & $1 \%$ & $(14$ couplets $)$ \\
33 & $4 \%$ & $(4$ tableaux $)$ & $1 \%$ & (16 couplets) \\
\hline other & $0 \%$ & $(0$ tableaux $)$ & $0 \%$ & (3 couplets) \\
\hline \hline Total & $100 \%$ & $(92$ tableaux $)$ & $100 \%$ & (1254 couplets) \\
\hline
\end{tabular}

The theory predics a four-way split between 44,33 (most frequent), $43^{\prime}, 3^{\prime} 3$ (medium), $\mathbf{3}^{\prime} \mathbf{3}^{\prime}, \mathbf{3 3}$ (rare), and all other couplet types (non-occurring). This prediction is right on the mark. The actual corpus percentages are well approximated although a little 'flattened'. So, with a minimum of extra assumptions, the constraint ranking needed for the categorical data also make sense of the observed frequency profile.

\section{Case 2: Isaac Watts}

The prolific 18th-century hymn composer Isaac Watts adapted the folk quatrain to neoclassical tastes by categorically eliminating the $\mathbf{3}^{\prime}$ foot type, thereby reducing the quatrain inventory to common meter (4343), long meter (4444), and short meter (3343), in that order of frequency. Since $\mathbf{3}^{\prime}$ feet violate FоотBin, Watts' more restrictive quatrains differ formally from folk quantrains in having the obligatory ranking FOOTBIN $\gg$ FAITHFULNESS. Combined with the folk song ranking SALIENCY $\gg$ FAITHFULNESS already established above, we obtain for Watts the ranking

\section{(18) SALIENCY $\gg$ FoOTBIN $\gg$ FAITHFULNESS}

which as before predicts a quantitative profile for the corpus. This profile can be calculated from (19) by the same procedure as before. The additional restriction in (18) reduces the permissible constraint rankings in this meter to just 21 , which are represented by the unshaded cells. 
(19)

\begin{tabular}{|c|c|c|c|c|c|c|c|}
\hline \multicolumn{4}{|c|}{ Ranking of markedness constraints } & \multicolumn{4}{|c|}{ Ranking of FAITHFULNESS } \\
\hline & & & & 2nd & $3 \mathrm{rd}$ & 4th & 5 th \\
\hline$\overline{\mathrm{SAL}}$ & MAX & FTBIN & PAR & $4343^{\prime} 3^{\prime} 3$ & $4343^{\prime} 3^{\prime} 3$ & 43 & 43 \\
\hline SAL & MAX & PAR & FTBIN & $4343^{\prime} 3^{\prime} 3$ & $4343^{\prime} 3^{\prime} 3$ & $4343^{\prime} 3^{\prime} 3$ & 43 \\
\hline SAL & FTBIN & MAX & PAR & $4343^{\prime} 3^{\prime} 3$ & 43 & 43 & 43 \\
\hline SAL & FTBIN & PAR & MAX & $4343^{\prime} 3^{\prime} 3$ & 43 & 43 & 43 \\
\hline SAL & PAR & MAX & FTBIN & $4343^{\prime} 3^{\prime} 3$ & $4343^{\prime} 3^{\prime} 3$ & $4343^{\prime} 3^{\prime} 3$ & 43 \\
\hline SAL & PAR & FTBIN & MAX & $4343^{\prime} 3^{\prime} 3$ & $4343^{\prime} 3^{\prime} 3$ & 43 & 43 \\
\hline MAX & SAL & FTBIN & PAR & 44 & 44 & 44 & 44 \\
\hline MAX & SAL & PAR & FTBIN & 44 & 44 & 44 & 44 \\
\hline FTBIN & SAL & PAR & MAX & 4443 & 43 & 43 & 43 \\
\hline FTBIN & SAL & MAX & PAR & 4443 & 43 & 43 & 43 \\
\hline PAR & SAL & MAX & FTBIN & $443^{\prime} 3^{\prime} 33$ & $443^{\prime} 3^{\prime} 33$ & 44 & 44 \\
\hline PAR & SAL & FTBIN & MAX & $443^{\prime} 3^{\prime} 33$ & $443^{\prime} 3^{\prime} 33$ & 4433 & 44 \\
\hline MAX & FTBIN & $\overline{\text { SAL }}$ & PAR & 44 & 44 & 44 & 44 \\
\hline MAX & PAR & SAL & FTBIN & 44 & 44 & 44 & 44 \\
\hline FTBIN & MAX & SAL & PAR & 44 & 44 & 44 & 44 \\
\hline FTBIN & PAR & SAL & MAX & 444333 & 4433 & 4433 & 44 \\
\hline PAR & MAX & SAL & FTBIN & $443^{\prime} 3^{\prime} 33$ & 44 & 44 & 44 \\
\hline PAR & FTBIN & SAL & MAX & $443^{\prime} 3^{\prime} 33$ & 4433 & 4433 & 44 \\
\hline $\mathrm{MAX}$ & FTBIN & PAR & $\mathrm{SAL}$ & 44 & 44 & 44 & 44 \\
\hline MAX & PAR & FTBIN & SAL & 44 & 44 & 44 & 44 \\
\hline FTBIN & MAX & PAR & SAL & 44 & 44 & 44 & 44 \\
\hline FTBIN & PAR & MAX & SAL & 4443 & 44 & 44 & 44 \\
\hline PAR & MAX & FTBIN & SAL & $443^{\prime} 3^{\prime} 33$ & 44 & 44 & 44 \\
\hline PAR & FTBIN & MAX & SAL & $443^{\prime} 3^{\prime} 33$ & 4433 & 44 & 44 \\
\hline
\end{tabular}

The predicted figures from (19) match the actual quantitative profile of the corpus well. The relative frequencies are exactly right. The promotion of FOOTBIN over FAITHFULNESS has the somewhat unexpected effect of raising the predicted frequency of $\mathbf{4 3}$ well above that of $\mathbf{4 4}$. Remarkably, this is exactly what we find in the corpus data. Even the actual percentages are almost correct. There is still a little 'flattening' but now it is reduced to $2 \%$.

(20)

\begin{tabular}{|c|c|c|}
\hline Type & frequency in tableaux & frequency in corpus \\
\hline 44 & $38 \%(8$ tableaux $)$ & $40 \% \quad(3,140$ couplets $)$ \\
\hline 43 & $57 \%$ (12 tableaux $)$ & $57 \%(4,538$ couplets $)$ \\
\hline 33 & $5 \%(1$ tableau $)$ & $3 \%$ (258 couplets) \\
\hline$\overline{43^{\prime}}$ & $0 \%$ (no tableaux) & $0 \%$ (no couplets) \\
\hline $3^{\prime} 3$ & $0 \%$ (no tableaux) & $0 \%$ (no couplets) \\
\hline $3^{\prime} 3^{\prime}$ & $0 \%$ (no tableaux) & $0 \%$ (no couplets) \\
\hline Total & $100 \%$ (21 tableaux) & $100 \%$ (7,936 couplets $)$ \\
\hline
\end{tabular}

The reason why the predictions are more accurate for Watts than for the folk songs may be that Watts' hymns are by a single author composing in an invariant stereotyped style, whereas the folk songs constitute a rather heterogenous corpus. 
These results come essentially free from the theory. The sole stipulation that we needed is that SALIENCY outranks PARALLELiSM both in the folk quatrain and in Watts' hymns. This restriction is probably not arbitrary, but motivated by the fact that these quatrains are meant to be sung. Saliency is arguably a more important cue in orally performed and transmitted verse than in verse that is printed and read, where stanzas are visually demarcated. If this is right, then the reverse ranking PARALLELISM $\gg$ SALIENCY might be expected to occur, if at all, in written poetry.

\section{Case 3: Old English}

My third case is a translation of Sohn's (1998) quantitative analysis of Beowulf into the OT approach to metrical variation explored here. Sohn gives the following frequency distribution of Sievers line types (excluding expanded subtypes).

\begin{tabular}{|c|c|}
\hline Type & frequency in corpus \\
\hline 2A $[\mathrm{SW}][\mathrm{SW}]$ & $36.5 \%(1,391$ verses $)$ \\
\hline $1 \mathrm{~A}[\mathrm{~S}][\mathrm{WSW}]$ & $11.1 \% \quad$ (426 verses) \\
\hline 3B [WSW][S] & (425 verses) \\
\hline 1D [S][SWW] & (523 verses) \\
\hline $2 \mathrm{C}[\mathrm{WS}][\mathrm{SW}]$ & (430 verses) \\
\hline $3 \mathrm{E} \quad[\mathrm{SWW}][\mathrm{S}]$ & (379 verses) \\
\hline 2B [WS][WS] & (128 verses) \\
\hline 2E $[\mathrm{SW}][\mathrm{WS}]$ & (106 verses) \\
\hline $\begin{array}{ll} & {[\mathrm{S}][\mathrm{WWS}]}\end{array}$ & $0 \%$ \\
\hline$-\quad[\mathrm{WWS}][\mathrm{S}]$ & $0 \%$ \\
\hline
\end{tabular}

Sohn derives the types from the undominated constraints in (22),

(22) Undominated constraints

a. PARSE: Every metrical constituent belongs to a metrical constituent of the next higher rank.

b. FILL: Every metrical constituent dominates a metrical constituent of the next lower rank.

c. BIN: A verse and a line is binary.

d. HeAdedness: A constituent has exactly one head (one $S$ ).

and relates the quantitative preferences to the dominated constraints in (23).

(23) Dominable (violated) constraints

a. *LAPSE: No adjacent Weak positions (*WW).

b. AlignHead: The left edge of a head is aligned with the left edge of its mother constituent.

Sohn assumes that the frequency of a type is inversely proportional to the number of constraints it violates. With a little tweaking this idea fits nicely into our approach. Supposing as before that unmetrical inputs are always ruled out by constraints that dominate FAITHFULNESS, we obtain tableau (24): 
(24)

\begin{tabular}{|lr||c|c|c|c|c|}
\hline Input: $[\mathbf{S}][\mathbf{S W}][\mathbf{S}]$ & BIN & HEAD & FAITH & LAPSE & ALIGNHEAD \\
\hline \hline $1 . r$ & {$[\mathbf{S}][\mathbf{S W}][\mathbf{S}]$} & $*$ & & & & \\
\hline 2. & {$[\mathbf{S W}][\mathbf{S W}]$} & & & $*$ & & \\
\hline $3 . \quad[\mathbf{S}][\mathbf{S W W}]$ & & & $*$ & $*$ & \\
\hline \hline
\end{tabular}

As before, metrical inputs are mapped into identical outputs just in case FAITHFULNESS dominates all constraints that exclude them.

\begin{tabular}{|lr||c|c|c|c|c|}
\hline Input: $[\mathbf{S}][\mathbf{S W W}]$ & BIN & HEAD & FAITH & LAPSE & ALIGNHEAD \\
\hline \hline 1. & {$[\mathbf{S}][\mathbf{S W}][\mathbf{S}]$} & $*$ & & $*$ & & \\
\hline 2. & {$[\mathbf{S W}][\mathbf{S W}]$} & & & $*$ & & \\
\hline 3. & {$[\mathbf{S}][\mathbf{S W W}]$} & & & & $*$ & \\
\hline \hline
\end{tabular}

Otherwise they are mapped into more harmonic outputs.

\begin{tabular}{|lr||c|c|c|c|c|}
\hline Input: [S][SWW] & BIN & HEAD & LAPSE & FAITH & ALIGNHEAD \\
\hline \hline $1 . r[\mathbf{S}][\mathbf{S W}][\mathbf{S}]$ & $*$ & & $*$ & & \\
\hline 2. & {$[\mathbf{S W}][\mathbf{S W}]$} & & & & $*$ & \\
\hline $3 . \quad[\mathbf{S}][\mathbf{S W W}]$ & & & $*$ & & \\
\hline \hline
\end{tabular}

The undominated constraints in (22) don't yet exclude the types [S][WWS] and [WWS][S]. These unmetrical verse types are just those which have three violations: in addition to LAPSE, they violate ALIGNHEAD twice. We can express this generalization by forming a new constraint, (27a) ALIGNHEAD $^{2}$ which prohibits multiple ALIGNHEAD violations - formally, by self-conjunction of AlignHEAD - and imposing the restriction (27b), that FAITHFUlNESS cannot dominate all markedness constraints.

(27) a. AlignHead ${ }^{2}$ : AlignHead may not be violated more than once.

b. FAITHFULNESS must be dominated.

The constraints AlignHead, AlignHeaD ${ }^{2}$, and *LAPSE are freely ranked, as long as (27a) is obeyed. The resulting outputs of rankings (for all inputs) are tabulated in (28). 
(28)

\begin{tabular}{|c|c|c|c|c|c|c|c|c|c|c|}
\hline \multicolumn{4}{|c|}{ Ranking of constraints } & \multicolumn{7}{|c|}{ Outputs } \\
\hline *LAPSE & FAITH & ALHD & $\mathrm{ALHD}^{2}$ & $2 \mathrm{~A}$ & $1 \mathrm{~A}$ & 3B & $2 \mathrm{C}$ & & & \\
\hline *LAPSE & FAITH & $\mathrm{ALHD}^{2}$ & ALHD & $2 \mathrm{~A}$ & $1 \mathrm{~A}$ & 3B & $2 \mathrm{C}$ & $2 \mathrm{~B}$ & & \\
\hline *LAPSE & ALHD & FAITH & $\mathrm{ALHD}^{2}$ & $2 \mathrm{~A}$ & & & & & & \\
\hline *LAPSE & $\mathrm{ALHD}^{2}$ & FAITH & ALHD & $2 \mathrm{~A}$ & $1 \mathrm{~A}$ & 3B & $2 \mathrm{C}$ & & & \\
\hline *LAPSE & ALHD & $\mathrm{ALHD}^{2}$ & FAITH & $2 \mathrm{~A}$ & & & & & & \\
\hline *LAPSE & $\mathrm{ALHD}^{2}$ & ALHD & FAITH & $2 \mathrm{~A}$ & & & & & & \\
\hline ALHD & FAITH & *LAPSE & $\mathrm{ALHD}^{2}$ & $2 \mathrm{~A}$ & 1D & $3 \mathrm{E}$ & & & & \\
\hline ALHD & FAITH & $\mathrm{ALHD}^{2}$ & $*$ LAPSE & $2 \mathrm{~A}$ & 1D & $3 \mathrm{E}$ & & & & \\
\hline ALHD & *LAPSE & FAITH & $\mathrm{ALHD}^{2}$ & $2 \mathrm{~A}$ & & & & & & \\
\hline ALHD & *LAPSE & $\mathrm{ALHD}^{2}$ & FAITH & $2 \mathrm{~A}$ & & & & & & \\
\hline ALHD & $\mathrm{ALHD}^{2}$ & FAITH & *LAPSE & $2 \mathrm{~A}$ & 1D & $3 \mathrm{E}$ & & & & \\
\hline ALHD & $\mathrm{ALHD}^{2}$ & *LAPSE & FAITH & $2 \mathrm{~A}$ & & & & & & \\
\hline $\mathrm{ALHD}^{2}$ & FAITH & *LAPSE & ALHD & $2 \mathrm{~A}$ & $1 \mathrm{~A}$ & 3B & 1D & $2 \mathrm{C}$ & $3 \mathrm{E}$ & $2 \mathrm{E}$ \\
\hline $\mathrm{ALHD}^{2}$ & FAITH & ALHD & *LAPSE & $2 \mathrm{~A}$ & $1 \mathrm{~A}$ & 3B & 1D & $2 \mathrm{C}$ & $3 \mathrm{E}$ & $2 \mathrm{E}$ \\
\hline $\mathrm{ALHD}^{2}$ & $*$ LAPSE & FAITH & ALHD & $2 \mathrm{~A}$ & $1 \mathrm{~A}$ & $3 \mathrm{~B}$ & $2 \mathrm{C}$ & & & \\
\hline $\mathrm{ALHD}^{2}$ & *LAPSE & ALHD & FAITH & $2 \mathrm{~A}$ & & & & & & \\
\hline $\mathrm{ALHD}^{2}$ & ALHD & FAITH & $*$ LAPSE & $2 \mathrm{~A}$ & 1D & $3 \mathrm{E}$ & & & & \\
\hline $\mathrm{ALHD}^{2}$ & ALHD & $*$ LAPSE & FAITH & $2 \mathrm{~A}$ & & & & & & \\
\hline
\end{tabular}

The prediction is again that the relative frequency of each line type is proportional to the total number of constraint rankings that allow it. The predicted and attested numbers are given in (29).

\begin{tabular}{|ll|rr|rr|}
\hline \multicolumn{2}{|c|}{ Type } & \multicolumn{2}{|c|}{ frequency in tableaux } & \multicolumn{2}{|c|}{ frequency in corpus } \\
\hline 2A & {$[\mathrm{SW}][\mathrm{SW}]$} & $34.6 \%$ & $(18$ tableaux $)$ & $36.5 \%$ & $(1,391$ verses $)$ \\
\hline 1A & {$[\mathrm{S}][\mathrm{WSW}]$} & $11.5 \%$ & $(6$ tableaux $)$ & $11.1 \%$ & $(426$ verses $)$ \\
3B & {$[\mathrm{WSW}][\mathrm{S}]$} & $11.5 \%$ & $(6$ tableaux $)$ & $11.1 \%$ & $(425$ verses $)$ \\
$1 \mathrm{D}$ & {$[\mathrm{S}][\mathrm{SWW}]$} & $11.5 \%$ & $(6$ tableaux $)$ & $13.8 \%$ & $(523$ verses $)$ \\
2C & {$[\mathrm{WS}][\mathrm{SW}]$} & $11.5 \%$ & $(6$ tableaux $)$ & $11.3 \%$ & $(430$ verses $)$ \\
3E & {$[\mathrm{SWW}][\mathrm{S}]$} & $11.5 \%$ & $(6$ tableaux $)$ & $10.0 \%$ & $(379$ verses $)$ \\
\hline 2B & {$[\mathrm{WS}][\mathrm{WS}]$} & $3.8 \%$ & $(2$ tableaux $)$ & $3.4 \%$ & $(128$ verses $)$ \\
2E & {$[\mathrm{SW}][\mathrm{WS}]$} & $3.8 \%$ & $(2$ tableaux $)$ & $2.8 \%$ & $(106$ verses $)$ \\
\hline- & {$[\mathrm{S}][\mathrm{WWS}]$} & $0 \%$ & $(0$ tableaux $)$ & $0 \%$ & - \\
- & {$[\mathrm{WWS}][\mathrm{S}]$} & $0 \%$ & $(0$ tableaux $)$ & $0 \%$ & - \\
\hline
\end{tabular}

As in the ballad quatrains, the partial ranking generates a four-way split between types 2A [SW][SW] (most frequent), 1A [S][WSW], 3B [WSW][S], 1D [S][SWW], 2C [WS][SW], 3E [SWW][S] (medium), 2B [WS][WS], 2E [SW][WS] (rare), and all the rest (non-occurring). This is clearly confirmed by the corpus data. Also, the predicted percentages are very close to the corpus percentages, with only $1 \%-2 \%$ 'flattening'.

We see again how the constraints that account for the categorical data contribute to explaining the observed frequency distribution. For example, ALIGNHEAD ${ }^{2}$, which was introduced to rule out the non-occurring [S][WWS] and [WWS][S], also contributes to explaining why [WSW][S] is disproportionately more frequent than [WS][WS]. 


\section{Case 4: Weight compensation in inverted feet: Finnish iambic verse}

Finnish poets differ considerably in whether and to what extent they allow iambic inversion in words of two or more syllables (Sadeniemi 1949, Leino 1982:206). To establish the pattern I collected all the polysyllabic inversions I could find from thirty-six Finnish 19th and 20th century poets. Altogether 6,233 instances were found, out of a total of 31,562 iambic lines. The use of inversions turned out to divide the poets into five crisply differentiated groups (Kiparsky 2005b).

a. Group O: No inversion in polysyllables. These poets (V.A. Koskenniemi, A. Hellaakoski, and H. Asunta) allow inversion only when the first word of the inverted foot is monosyllabic.

b. Group I: Inversion only in LH- polysyllables, i.e. words with a Light first syllable and a Heavy second syllable. I found only one poet with this maximally restrictive polysyllabic inversion system, Yrjö Jylhä.

c. Group II: inversion allowed in L- polysyllables (beginning with a light syllable). This group includes O. Manninen, U. Kailas, L. Viljanen, S. Harmaja, T. Lyy, O. Paloheimo, and K. Sarkia up to 1937.

d. Group III: inversion allowed in L- and HH- (i.e. it is prohibited only in HL- polysyllables): A. Noponen, H. Haahti, H. Hiisku, E. Leino, K. Kaatra, E.Sinervo, L. Pohjanpää, J. Erkko, I. Pimiä, A. Oksanen, P. Cajander, K. Sarkia in his later work, J. Siljo, E. Vaara, early E. Lönnrot, and U. Kupiainen.

e. Group $I V$ : inversion allowed in any type of polysyllable. This group includes A. Tynni, E. Vuorela, A. Kivimaa, H. Liinamaa, K. Kramsu, H. Juvonen, J. Haavio, L. Onerva, A. Kajanto, P. Mustapää, and E. Lönnrot in his later work.

Here is an extreme example of all four types of polysyllabic inversion in the space of a few lines.

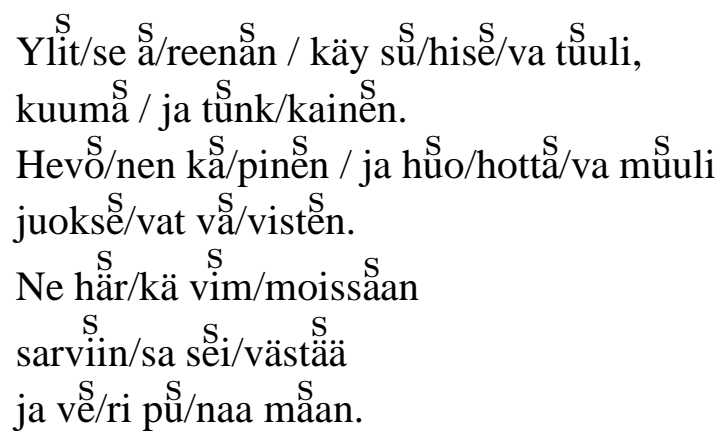

(P. Mustapää, Kuoleva Kantaäiti)

The treatment of inversion is a consistent feature of a poet's metrical practice, stable except for two poets who relax their usage by one notch in mid-career. ${ }^{3}$ Table (32) shows how often each group inverts polysyllables of the four weight patterns.

\footnotetext{
${ }^{3}$ In his early lyrics (up to 1845) Lönnrot belongs to Group III, in his later verse (from 1857), notably his experiments in hymn writing, he switches to Group IV. Sarkia starts out in Group II, and then, after his Italian journey which profoundly changed the character of his poetry, he adopts the looser style of Group III. These poets are therefore listed under two groups in (32).
} 


\begin{tabular}{rr|rrrr|rrr} 
Group & $N$ & W s & w s & ws & w S & & \\
\hline O. & 3 & $0.0 \%$ & $0.0 \%$ & $0.0 \%$ & $0.0 \%$ & 0 & 3,149 & $0.0 \%$ \\
I. & 1 & $0.0 \%$ & $0.0 \%$ & $0.0 \%$ & $100.0 \%$ & 99 & 227 & $43.6 \%$ \\
II. & 7 & $0.0 \%$ & $0.1 \%$ & $20.9 \%$ & $79.0 \%$ & 841 & 5,492 & $15.3 \%$ \\
III. & 16 & $0.0 \%$ & $16.1 \%$ & $24.7 \%$ & $59.2 \%$ & 3,257 & 15,124 & $21.5 \%$ \\
IV. & 11 & $11.7 \%$ & $27.8 \%$ & $22.6 \%$ & $37.9 \%$ & 2,036 & 7,570 & $26.9 \%$ \\
\hline Total & 38 & & & & & 6,233 & 31,562 & $19.7 \%$
\end{tabular}

The five categorical systems in (30) are describable by correspondence constraints of the following general type:

(33) A Weak position cannot be affiliated with a stressed syllable, except at the beginning of a line,

a. in a monosyllabic word, ${ }^{4}$

b. in a polysyllabic word that satisfies certain weight conditions.

The most restrictive norm represented by Group $\mathrm{O}$ is identical to that of most Russian and German verse. The departures from it are motivated by the phonology of Finnish. Because every word begins with a stressed syllable, obedience to the unmitigated (33a) forces all iambic lines to begin with a monosyllabic word, which tends to produce tiresome verse. (33b) ensures that some of the polysyllabic vocabulary becomes available at the beginnings of iambic lines. The variants of (33b) follow a strict implicational hierarchy. If any inversion in polysyllables is allowed at all, it is allowed in polysyllables which begin with a sequence of a Light syllable and a Heavy syllable, where the mismatch between stress and the Weak/Strong metrical pattern is maximally compensated for by the harmonizing syllable weight relations. In the other groups the license is extended to successively more drastic quantitative mismatches.

An Optimality-Theoretic account for the varieties of iambs in (30) requires the constraints in $(34){ }^{5}$

(34) Correspondence constraints on polysyllabic words:
a. * $\sigma$ : No stressed syllables in Weak position,
$\mathrm{W}$
b. * ${ }^{H}$ : No stressed heavy syllables in Weak position.
$\mathrm{S}$
c. *L: No unstressed light syllables in Strong position.
W S
d. *HL: No combined violations of (b) and (c) (constraint conjunction).

All four constraints in (34) are required for Finnish meter independently of the variation data. $(34 a, b, d)$ are needed for the categorical properties in (30). In particular, the conjoined constraint (34d) is needed for the exclusion of initial HL- in the meter of Group III. Constraint (34c) is

\footnotetext{
${ }^{4}$ Note that its English counterpart contains precisely the same conditions, but linked disjunctively instead of conjunctively ("A Weak position must not be affiliated with a stressed syllable, except at the beginning of a line, or in a monosyllabic word").

${ }^{5}$ Formally, (34b) and (34c) are themselves conjoined from (34a) and two constraints which restrict just syllable weight. The latter apply to monosyllabic words as weaker analogs of the constraints in (34). However, quantity in monosyllabic words is not categorically regimented, but a matter of preferences. I hope to return to these preferences in a separate study.

${ }^{5}$ Note that the conjunctive constraint $(34 \mathrm{~d})$ is analogous to the conjunctive constraint (33a); in both cases the individual conjuncts function separately elsewhere (see fn. 4).
} 
undominated in iambic-anapestic verse (Hanson \& Kiparsky 1996), and it plays a major role in shaping the quantitative profile of iambic verse and trochaic verse (for the latter, see Kiparsky 2005b). These same constraints, where freely ranked, also generate the variation patterns within each group.

The most restrictive system of (30) is that of group $\mathrm{O}$, which completely excludes polysyllabic inversion. Formally, this means that the most restrictive markedness constraint $* \sigma \quad$ outranks FAITHFULNESS. Groups I-IV have the reverse ranking $* \dot{w} \gg$ FAITHFULNESS.

a. Group O: no polysyllabic inversion $\mathrm{W}$ $*^{\prime} \sigma^{\gg} \gg$ FAITHFULNESS

b. Groups I-IV: polysyllabic inversion allowed

$$
\text { FAITHFULNESS } \gg * *^{\mathrm{W}}
$$

The most restrictive of the latter groups is I, where all the remaining markedness constraints still outrank FAITHFULNESS. The other systems are obtained by additional stepwise relaxation of the rankings of the markedness constraints with respect to FAITHFULNESS. ${ }^{6}$ In the most liberal system (group IV), none of the markedness constraints are required to outrank FAITHFULNESS, hence all inversions are allowed. The intermediate systems allow progressively more marked inversions. The distribution of permitted and prohibited rankings of the markedness constraints with FAITHFULNESS account for the quantitative profiles of the each systems. The following additional ranking restrictions characterize groups I-IV.
a. Group I: polysyllabic inversion only in LH-
W $\mathrm{S}$ W
$*$ HL $, * \dot{H}, * \mathrm{~L} \gg$ FAITHFULNESS

b. Group II: polysyllabic inversion only in LW S W

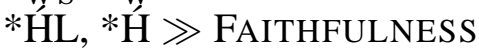

c. Group III: polysyllabic inversion in L- and HHW S

*HL $\gg$ FAITHFULNESS

d. Group IV: polysyllables of any kind may invert (none)

Tableau (37) displays the possible rankings of (34b-c) and FAITHFULNESS and their outputs. The predicted relative frequencies of each line type for a given group of poets can be calculated from the tableau by erasing the cells that represent rankings which are inconsistent with its metrical grammar in (36). Counting the outputs in the remaining cells gives the predicted proportions for each group. The resulting numbers for the groups with interesting variation (groups II, II, and IV) are shown at the bottom of the chart.

\footnotetext{
${ }^{6}$ This is at least heuristically a convenient way of visualizing the relationship between the systems. It may also correspond, at least loosely, to the historical evolution by which the strict type $\mathrm{O}$ iambic meter was progressively relaxed in order to adapt it to a language with obligatory initial stress.
} 


\begin{tabular}{|c|c|c|c|c|c|c|c|}
\hline \multicolumn{4}{|c|}{ Ranking of constraints } & \multicolumn{4}{|c|}{ Outputs } \\
\hline $\begin{array}{l}\text { WS } \\
* \mathrm{HL}\end{array}$ & $* \stackrel{W}{\mathrm{~W}}$ & $* \mathrm{~S}$ & FAITH & - & - & - & $\begin{array}{l}\text { WS } \\
\text { LH }\end{array}$ \\
\hline W S & $\mathrm{W}$ & & $\mathrm{S}$ & & & Ws & W S \\
\hline *H́L & $* \dot{\mathrm{H}}$ & FAITH & $* \mathrm{~L}$ & - & - & LL & ĹH \\
\hline WS & $\mathrm{S}$ & W & & & & & WS \\
\hline *HL & $* \mathrm{~L}$ & $* \mathrm{H}$ & FAITH & - & - & - & LH \\
\hline 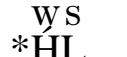 & $\begin{array}{r}\mathrm{S} \\
* \mathrm{I}\end{array}$ & & $* \stackrel{W}{H}$ & 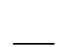 & He & - & $\begin{array}{l}\text { WS } \\
\text { I }\end{array}$ \\
\hline${ }^{*} \mathrm{HL}$ & $* \mathrm{~L}$ & $\begin{array}{l}\text { FAITH } \\
\text { W }\end{array}$ & $\begin{array}{c}{ }^{*} \mathrm{H} \\
\mathrm{S}\end{array}$ & - & W S & $\overline{\mathrm{wS}}$ & $\begin{array}{l}\text { LH } \\
\text { ws }\end{array}$ \\
\hline$* \mathrm{HL}$ & FAITH & $* \dot{\mathrm{H}}$ & $* \mathrm{~L}$ & - & ḦH & LL & ĹH \\
\hline W S & & $\mathrm{S}$ & $\mathrm{W}$ & & W S & WS & Ws \\
\hline$* \hat{\mathrm{HL}}$ & FAITH & $* \mathrm{~L}$ & $* \mathrm{H}$ & - & $\mathrm{HH}$ & LL & LH \\
\hline$W$ & 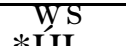 & & $S_{*}^{S}$ & & & WS & Ws \\
\hline$* \mathrm{H}$ & *HL & FAITH & $* \mathrm{~L}$ & - & - & LL & $\mathrm{LH}$ \\
\hline * & $\begin{array}{l}\text { WS S } \\
* H \mathrm{HL}\end{array}$ & & FAITH & - & - & - & L \\
\hline W & $\mathrm{S}$ & W S & & & & & W S \\
\hline$* \hat{H}$ & $* \mathrm{~L}$ & *H́ & FAITH & - & - & - & LH \\
\hline W & $\mathrm{S}$ & & W S & & & & W S \\
\hline$* \mathrm{H}$ & $* \mathrm{~L}$ & FAITH & $* \mathrm{HL}$ & - & - & - & LH \\
\hline$\underset{*}{W}$ & & WS & $\underset{*}{S}$ & & & WS & WS \\
\hline${ }^{*} \mathrm{H}$ & FAITH & $* \mathrm{HL}$ & $* \mathrm{~L}$ & - & - & LL & LH \\
\hline$* \stackrel{W}{\mathrm{H}}$ & FAITH & $\begin{array}{r}\mathrm{S} \\
* \mathrm{~L}\end{array}$ & $\begin{array}{l}\text { W S } \\
* \mathrm{HL}\end{array}$ & & - & $\begin{array}{l}\text { WS } \\
\text { LI }\end{array}$ & $\begin{array}{l}\text { WS } \\
\text { LH }\end{array}$ \\
\hline & WS & W & & & & & Ws \\
\hline$* \mathrm{~L}$ & *HL & $* \hat{H}$ & FAITH & - & - & - & LH \\
\hline $\mathrm{S}$ & W S & & W & & W s & & WS \\
\hline$* \mathrm{~L}$ & *HL & FAITH & & - & $\mathrm{HH}$ & - & $\mathrm{LH}$ \\
\hline $\begin{array}{r}\mathrm{S} \\
* \mathrm{I}\end{array}$ & $* \underset{W}{H}$ & 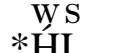 & FAITH & - & $\bar{T}$ & $\overline{-}$ & WS \\
\hline $\begin{array}{l}\mathrm{L} \\
\mathrm{S}\end{array}$ & W & & W S & - & - & - & W S \\
\hline$* \mathrm{~L}$ & $* \dot{H}$ & FAITH & *H́L & - & - & - & ĹH \\
\hline $\mathrm{S}$ & & W & W S & & W S & & W S \\
\hline$* \mathrm{~L}$ & FAITH & $* \dot{\mathrm{H}}$ & $* \mathrm{HL}$ & - & $\mathrm{HH}$ & - & LH \\
\hline $\begin{array}{r}\mathrm{S} \\
* \mathrm{~L}\end{array}$ & & $\begin{array}{l}\text { WS } \\
* \stackrel{H}{H}\end{array}$ & $* \stackrel{W}{H}$ & $\longrightarrow$ & $\begin{array}{l}\text { W S } \\
\text { HH }\end{array}$ & - & $\begin{array}{l}\text { WS } \\
\text { I H }\end{array}$ \\
\hline & WS & $W$ & $S$ & WS & WS & Ws & WS \\
\hline FAITH & *HL & $* \dot{\mathrm{H}}$ & $* \mathrm{~L}$ & HL & HH & ĹL & L'H \\
\hline & W S & $\mathrm{S}$ & W & W S & W S & WS & W S \\
\hline FAITH & $* \mathrm{HL}$ & $* \mathrm{~L}$ & $* \mathrm{H}$ & HL & $\mathrm{HH}$ & LL & LH \\
\hline & $\begin{array}{c}W \\
* \dot{U}\end{array}$ & WS & $\mathrm{S}$ & WS & W S & WS & WS \\
\hline FАITH & ${ }^{*} \mathrm{H}$ & $* \mathrm{HL}$ & $* \mathrm{~L}$ & HL & $\mathrm{HH}$ & LL & LH \\
\hline FAITH & $* \stackrel{\mathrm{H}}{ }$ & $* \mathrm{~s}$ & $* \hat{\mathrm{H}}$ & HI & $\begin{array}{l}\text { ws } \\
\text { HH }\end{array}$ & $\begin{array}{l}\text { WS } \\
\text { LIL }\end{array}$ & L'H \\
\hline & $\mathrm{S}$ & W S & $\mathrm{W}$ & W S & W S & WS & W S \\
\hline FAITH & ${ }^{*} \mathrm{~L}$ & $*$ HL & $* \hat{\mathrm{H}}$ & HL & HH & LL & LH \\
\hline & $\begin{array}{r}\mathrm{S} \\
* \mathrm{I}\end{array}$ & *W & 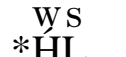 & $\begin{array}{l}\text { Ws } \\
\text { HI }\end{array}$ & $\begin{array}{l}\text { W S } \\
\text { HH }\end{array}$ & WS & $\begin{array}{l}\text { WS } \\
\text { I'H }\end{array}$ \\
\hline FAITH & ${ }^{*} \mathrm{~L}$ & ${ }^{2} \mathrm{H}$ & ${ }^{*} \mathrm{HL}$ & HL & ПН & LL & \\
\hline II: $(36 \mathrm{~b}$ & & & & 0 & 0 & 2 & 8 \\
\hline III: (36 & & & & 0 & 4 & 4 & 12 \\
\hline IV: $(36$ & & & & 6 & 12 & 12 & 24 \\
\hline
\end{tabular}

The match between expected and observed frequencies is satisfactory: 


\begin{tabular}{|c|c|c|c|c|c|c|c|c|}
\hline & \multicolumn{4}{|c|}{$\begin{array}{l}\text { Expected frequencies } \\
\text { (from tableau (37)) }\end{array}$} & \multicolumn{4}{|c|}{$\begin{array}{l}\text { Observed frequencies } \\
\text { (from table (32)) }\end{array}$} \\
\hline II. & $0.0 \%$ & $0.0 \%$ & $20 \%$ & $80 \%$ & $0.0 \%$ & $0.1 \%$ & $20.9 \%$ & $79.0 \%$ \\
\hline III. & $0.0 \%$ & $20.0 \%$ & $20.0 \%$ & $60.0 \%$ & $0.0 \%$ & $16.1 \%$ & $24.7 \%$ & $59.2 \%$ \\
\hline IV. & $11.1 \%$ & $22.2 \%$ & $22.2 \%$ & $44.4 \%$ & $11.7 \%$ & $27.8 \%$ & $22.6 \%$ & $37.9 \%$ \\
\hline
\end{tabular}

These expected frequencies are what we get directly from the theory if we stipulate no rankings beyond what the categorical restrictions require. More accurate matches to the observed data can be obtained by additional constraint rankings. For example, if we assume that group IV im-

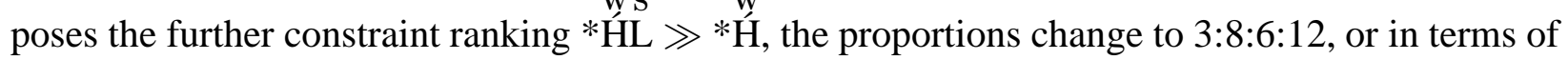
percentages 10.3\%:27.6\%:20.7\%:41.4, an improvement over (38).

Whether this additional step is ultimately justified is a question that I prefer to leave open for now. The Finnish corpus from which I extracted these statistics is not homogeneous. The frequencies for the groups sum up the varying usage of many poets with varying styles. Most of the individual-level variation can be modeled by slight adjustments of the partial rankings. The averaged corpus figures do represent a kind of overall statistical norm for each of the systems. These exact numbers should not be taken too seriously because they partly depend on accidental factors, such as how many lines the various poets happened to publish and how much of their work was available in the libraries. Yet the fact that each of the statistical norms is approximated by the free interaction of the very same set of constraints that are elsewhere undominated supports the partial ranking approach to variation.

\section{Conclusions}

- At least some types of metrical variation reflect competing preferences. In such cases, complex statistical patterns can be modeled by the interaction of partially ranked violable constraints. The proportion of tableaux consistent with the partially ranked constraints that generate a give output predicts it frequency of use.

- Metrical systems are typically structured by a small number of fairly well-understood categorical constraints on the distribution of prominent syllables and feet. They show regular disparities in frequency among the variants that conform to the categorical restrictions. In such domains, the discrete constraints that derive the categorical restrictions can be expected to predict the statistical data with some accuracy.

- In the cases investigated, this turned out to be the case. We found that once the minimum constraint rankings for the categorical metrical restrictions are specified, a reasonably close match to observed pattern of preferences among the remaining permissible variants is derived with few or no additional constraint rankings.

- The partial ranking approach relates frequency intrinsically to unmarkedness, hence explains why the most frequent outputs are typically the ones which violate the fewest constraints.

- The partial ranking model forms the basis of a restrictive theory of variation which derives its systematic patterning from minimal assumptions. Stochastic OT does not offer a comparably explanatory account. 
- The partial ranking approach derives variation patterns from the lack of specified ranking between constraints, and hence entails that they can be acquired without tracking frequencies: an attractive feature for metrical systems, which are often acquired from small samples.

- These results support the larger hypothesis that grammars do not have a probabilistic component. Speakers/hearers/learners may not learn frequencies directly. Rather, they may establish preferences and a partial ranking between them (i.e. preferences among preferences) which have quantitative consequences in the use of language. 


\section{References}

Anttila, ARTO. 1997. Variation in Finnish Phonology and Morphology. Ph.D. Dissertation, Stanford University.

AntTILA, ARTO. 2002. Variation in phonological theory. In J.K. Chambers, Peter Trudgill, and Natalie Schilling-Estes (eds) The handbook of language variation and change. Malden, Mass.: Blackwell Publishers.

HANSON, KRISTIN, AND PAUl KiPARSKY. 1996. A theory of metrical choice. Language 72.287335.

Hayes, Bruce \& Margaret MacEachern. 1998. Quatrain form in English folk verse. Language 74.473-507. With appendices in http://www.humnet.ucla.edu/humnet/ linguistics/people/hayes/metrics.htm.

Hayes, BRuCE. 2002. In Kristin Hanson and Sharon Inkelas (edd.), The nature of the word. Cambridge, Mass.: MIT Press.

KIPARSKY, PAUl. 2005a. A modular metrics for folk verse. In B. Elan Dresher and Nila Friedberg (eds.) Formal approaches to poetry. Berlin: Mouton de Gruyter.

KIPARSKY, PAUL. 2005b. Iambic inversion in Finnish. Festschrift for NN.

Leino, PentTI. 1982. Kieli, runo ja mitta: suomen kielen metriikka. Pieksämäki.

LEINO, PENTTI. 1986. Language and metre: metrics and the metrical system of Finnish. Translated by Andrew Chesterman from Leino (1982). Helsinki: Suomalaisen Kirjallisuuden Seura.

Sohn, Chang Yong. 1998. The Metrical Structure of Beowulf. Ph.D. Thesis, Stanford. 